\title{
A Corrective Cosmetic Improves the Quality of Life and Skin Quality of Subjects with Facial Blemishes Caused by Skin Disorders
}

This article was published in the following Dove Press journal: Clinical, Cosmetic and Investigational Dermatology

\author{
Cristea Andra' \\ Anna Suwalska ${ }^{2}$ \\ Ana Maria Dumitrescu ${ }^{3}$ \\ Delphine Kerob ${ }^{4}$ \\ Catherine Delva ${ }^{5}$ \\ Marta Hasse-Cieślińska (iD ${ }^{6}$ \\ Agnes Solymosi ${ }^{7}$ \\ Monika Arenbergerova ${ }^{8}$ \\ 'Private Practice, Bucharest, Romania; \\ ${ }^{2}$ Primaderm, Warszawa, Poland; ${ }^{3}$ DClinic, \\ Bucharest, Romania; ${ }^{4}$ Laboratoires Vichy, \\ Levallois-Perret, France; ${ }^{5}$ Sylia-Stat, \\ Bourg la Reine, France; ${ }^{6}$ Proderma, \\ Poznań, Poland; ${ }^{7}$ Private Practice, \\ Budapest, Hungary; ${ }^{8}$ Third Faculty of \\ Medicine, Charles University and \\ Kralovske Vinohrady University Hospital, \\ Department of Dermatovenereology, \\ Prague, Czech Republic
}

Background: Facial blemishes resulting from skin disorders have a significant effect on the patient's self-esteem and impact quality of life (QOL).

Aim: To assess the impact of a corrective cosmetic (CC) on QOL on top of skin quality parameters.

Methods: An international observational study was conducted on subjects with visible facial flaws that would benefit from a corrective cosmetic. Investigators collected data regarding demographics, QOL using the Skindex-16 scale, skin dryness and tautness, subject and investigator satisfaction, cosmetic acceptability and tolerance at baseline and after 4 to 6 weeks of daily use.

Results: A total of 1840 subjects participated; the mean age was $31.5 \pm 11.1$ and $95 \%$ were women. Acne accounted for $48.9 \%$ of skin conditions, followed by melasma $(16.7 \%)$ and rosacea $(15.3 \%)$. Of the subjects $81.2 \%$ had at least $10 \%$ of the face affected and the condition was rated as disfiguring by $45.3 \%$ of the subjects; $45.0 \%$ and $44.4 \%$, respectively, had neither taut nor dry skin at baseline. Baseline Skindex-16 scores for symptoms, emotions, functioning and overall were $1.4 \pm 1.3,3.5 \pm 1.6,2.4 \pm 1.8$ and $2.4 \pm 1.3$, respectively, on a scale from 0 to 6 . Compliance was $96.0 \pm 10.6 \%$. At the end of the study, Skindex-16 scores had significantly $(\mathrm{p}<0.0001)$ improved for all parameters, as did skin dryness and tautness. Subject and investigator satisfaction were high or very high; cosmetic acceptability was high or very high and local tolerance good or very good.

Conclusion: The tested corrective cosmetic significantly improved the QOL of subjects with significant facial flaws, skin tautness and dryness, and was well tolerated.

Keywords: corrective cosmetic, dermatoses, quality of life, SKINDEX-16

\section{Introduction}

Facial blemishes including acne, angioma, rosacea, hyperpigmentation, vitiligo and other skin disorders may cause psychological impairment. ${ }^{1}$ Such impairment may have a significant impact on a patient's quality of life (QOL), on their relationships with others, self-image, and self-esteem, and may cause depression and/or emotional distress. $^{2-5}$ Several studies have demonstrated that corrective makeup or cosmetic camouflage results in the improvement of QOL in subjects with pigmentary disorders, in particular vitiligo, acne, scars, vascular disorders or after chemotherapy. But these studies were often conducted in small populations. ${ }^{6-11}$

Despite the proven ability of corrective cosmetics to improve QOL, patients may be discouraged to use them by their healthcare professional as they are still considered as aggravating the condition if not chosen and applied correctly. ${ }^{5}$
Correspondence: Monika Arenbergerova Email arenbergerova@email.cz 
The tested highly corrective cosmetic product (Dermablend $^{\circledR}$, Vichy Laboratoires, France, hereafter referred to as "CC") is available in different formulations (3D formulation for acne, containing salicylic acid and eperuline, and stick and fluid corrector formulations for skin conditions other than acne) and shades, and is adapted for each skin type and each indication. Fluid and stick formulations contain mineral filters such as titanium dioxide and iron oxide to protect against UV and visible light. ${ }^{12}$ Moreover, it does not affect the structure of the physiological function of the skin, is non-comedogenic, highly photoprotective and safe as reported by Duteil et al and in yet unpublished data. ${ }^{12}$

In 2005, CC was tested for the first time in a small study of 63 subjects with severe facial disorders including acne, dermatosis papulosis, hypopigmentation, lentigines, melasma, rosacea, vascular proliferations or other facial scars. Results after 3 months showed a significant $(\mathrm{p}<0.01)$ improvement in Skindex-16 scores. ${ }^{13}$

The aim of the present study was to confirm the improvement in QOL in a large panel of subjects with facial blemishes due to skin disorders, after a period of 4 weeks. Moreover, the study assessed subject and investigator satisfaction, cosmetic acceptability, skin quality and tolerance of the $\mathrm{CC}$.

\section{Methodology}

Between January and November 2018, a large, international, prospective, anonymous, non-interventional and observational survey assessed the impact of a $\mathrm{CC}$ on QOL, using the Skindex-16, as well as on skin dryness and tautness. ${ }^{14}$

The Skindex-16 is an abbreviated version of the Skindex-29 and is composed of 16 questions to which a majority of patients would have chosen the same response when responding to Skindex-29, and measurement of bother rather than frequency of patient experiences. It evaluates symptoms, emotional well-being, and functioning on a scale ranging from $0=$ not bothered at all to $10=$ very much bothered.

The survey was conducted according to the guidelines of the International Epidemiological Association for proper conduct in epidemiological research and required in Europe no ethics committee approval for this type of investigation; subjects gave written informed consent to participate in this survey. ${ }^{15}$

Adult subjects with visible facial flaws including, but not limited to, acne, rosacea, hyperpigmentation, angioma or vitiligo and who could benefit from $\mathrm{CC}$ were invited to participate. At baseline, investigators proposed one of the different formulas of the $\mathrm{CC}$ according to their indication and instructed the subjects to apply the $\mathrm{CC}$ once daily on the entire face.

Demographics, QOL, skin dryness and tautness were assessed at baseline. Subject and investigator satisfaction, cosmetic acceptability, application frequency and tolerance were assessed at baseline and after 4 weeks.

Statistical analyses were conducted using SAS software (version 9.4, SAS Institute Inc., Cary, NC). Qualitative variables were described as numbers and percentages of the different response modalities. A 95\% confidence intervals were calculated if necessary. Quantitative variables were described as numbers, means, standard deviations, medians, minimums, maximums and numbers of missing data. Quantitative data evolution was studied by a paired samples $t$-test or a paired samples Wilcoxon test in case of nonparametric distribution. Multinomial data evolution was studied by a generalized mixed model for multinomial data. All statistical analyses were performed at the 5\% significance using 2-sided tests, except normality which was tested at the threshold of 1\% using the Shapiro-Wilk test.

\section{Results}

Overall, 1840 subjects, mainly women (95\%, 1704/1793) with a mean age of $31.5 \pm 11.1$ years participated. The acne accounted for $48.9 \%(900 / 1840)$ of subjects with skin conditions. The other diagnoses included 16.7\% (307/1840) of subjects with melasma, $15.3 \%$ (282/1840) with rosacea, $14.8 \%(272 / 1840)$ with post-inflammatory hyperpigmentation and 9.7\% (178/1840) with angioma; other skin conditions (such as vitiligo, hypopigmentation, etc.) impacted 5\% or less of the subjects. A total of $81.2 \%(1489 / 1834)$ had at least $10 \%$ of the face affected, $45.3 \%(827 / 1826)$ considered the condition as disfiguring; $18.4 \%$ had taut and $21.2 \%$, had dry skin. Detailed demographic and skin characteristics at baseline are provided in Table 1. Baseline Skindex-16 scores for symptoms, emotions, functioning and globally were 1.4 $\pm 1.3,3.5 \pm 1.6,2.4 \pm 1.8$ and $2.4 \pm 1.3$, respectively (Table 2 ). One subject aged 12 years accounted for demographic data analysis but was excluded from the benefit analysis. This subject was considered a protocol violator.

Overall, 81.6\% (1446/1773) applied the CC once daily after 4 weeks, Skindex-16 scores had significantly $(\mathrm{p}<0.0001)$ improved by $0.7,1.8,1.4$ and 1.3 points for symptoms, emotions, functioning and globally, respectively (Figure 1). The prevalence of subjects with skin tautness had decreased by 
Table I Demographic and Skin Characteristics at Baseline

\begin{tabular}{|c|c|}
\hline Parameters & Values \\
\hline Gender (n, \%) & $N=1793$ \\
\hline Male & $89(5.0 \%)$ \\
\hline Female & $1704(95.0 \%)$ \\
\hline Age (years) & $N=|8| \mid$ \\
\hline Mean \pm SD & $31.5 \pm 11.1$ \\
\hline Min;Max & $12.0 ; 78.0$ \\
\hline Median & 30.0 \\
\hline Age distribution (n, \%) & $N=|8| \mid$ \\
\hline$<20$ years & $254(14.0 \%)$ \\
\hline $20-29$ & $641(35.4 \%)$ \\
\hline $30-39$ & $500(27.6 \%)$ \\
\hline$\geq 40$ & $416(23.0 \%)$ \\
\hline Skin condition (n, \%)* & $N=1840$ \\
\hline Acne & 900 (48.9\%) \\
\hline Rosacea & $282(15.3 \%)$ \\
\hline Other inflammatory skin diseases & $32(1.7 \%)$ \\
\hline Vitiligo & $97(5.3 \%)$ \\
\hline Other hypopigmentation & $93(5.1 \%)$ \\
\hline Melasma & $307(16.7 \%)$ \\
\hline Post-inflammatory hyperpigmentation & $272(14.8 \%)$ \\
\hline Other hyperpigmentation & $104(5.7 \%)$ \\
\hline Angioma & $178(9.7 \%)$ \\
\hline Scars & $223(12.1 \%)$ \\
\hline Other skin conditions & $46(2.5 \%)$ \\
\hline Surface of face affected (n, \%) & $N=1834$ \\
\hline$<10 \%$ & $344(18.8 \%)$ \\
\hline $10-29 \%$ & $724(39.5 \%)$ \\
\hline $30-49 \%$ & $565(30.8 \%)$ \\
\hline $50-80 \%$ & $167(9.1 \%)$ \\
\hline$>80 \%$ & 34 (1.9\%) \\
\hline Intensity (n, \%) & $N=1826$ \\
\hline Minor flaw & 999 (54.7\%) \\
\hline Disfiguring flaw & $670(36.7 \%)$ \\
\hline Very disfiguring flaw & I 44 (7.9\%) \\
\hline Extremely disfiguring flaw & $13(0.7 \%)$ \\
\hline Taut skin (n, \%) & $N=1836$ \\
\hline Not at all & $826(45.0 \%)$ \\
\hline Not much & $672(36.6 \%)$ \\
\hline Yes & $301(16.4 \%)$ \\
\hline Yes, very taut & 37 (2.0\%) \\
\hline Dry skin (n, \%) & $N=1833$ \\
\hline Not at all & 814 (44.4\%) \\
\hline Not much & $631(34.4 \%)$ \\
\hline Yes & 347 (18.9\%) \\
\hline Yes, very dry & $4 \mathrm{I}(2.2 \%)$ \\
\hline
\end{tabular}

Note: *More than one skin condition possible by subject.
Table 2 Skindex-16 Scores at Baseline*

\begin{tabular}{|c|l|}
\hline Skindex-16 score & Values \\
\hline Symptoms & $\mathrm{N}=1836$ \\
Mean $\pm \mathrm{D}$ & $1.4 \pm 1.3$ \\
Min;Max & $0.0 ; 6.0$ \\
Median & 1.0 \\
\hline Emotions & $\mathrm{N}=1833$ \\
Mean $\pm S D$ & $3.5 \pm 1.6$ \\
Min;Max & $0.0 ; 6.0$ \\
Median & 3.7 \\
\hline Functioning & $\mathrm{N}=1831$ \\
Mean $\pm S D$ & $2.4 \pm 1.8$ \\
Min;Max & $0.0 ; 6.0$ \\
Median & 2.0 \\
\hline Global Score & $\mathrm{N}=1831$ \\
Mean $\pm S D$ & $2.4 \pm 1.3$ \\
Min;Max & $0.0 ; 6.0$ \\
Median & 2.4 \\
\hline
\end{tabular}

Note: *Scores ranging from $0=$ not bothered to $10=$ very much bothered.

$14.8 \%$ to $3.6 \%$ and by $16.5 \%$ to $4.7 \%$ for those with dry skin (Figure 2); differences were statistically significant ( $\mathrm{p}<0.0001)$. Subject satisfaction was $8.8 \pm 1.4$ on an 11-point scale; $98.7 \%$ (161/163) of the investigators were satisfied or highly satisfied with the CC. According to the latter, CC had a satisfying or very satisfying impact on the well-being of subjects with acne $(95.8 \%, 159 / 166)$, rosacea $(95.7 \%, 132 / 138)$, hypopigmentation (95.1\%, 117/123), hyperpigmentation $(94.1 \%, 144 / 153)$ and angioma $(88.9 \%, 80 / 90)$. In total, $95.0 \%(1741 / 1835)$ of all subjects were satisfied or highly satisfied with the cosmetic quality of the tested CC and $96.0 \%(1761 / 1835)$ stated that the $\mathrm{CC}$ had met their expectations.

Local tolerance was excellent in $97.7 \%$ of all subjects.

\section{Discussion}

Results from our study confirmed in a large cohort of subjects with facial blemishes caused by skin disorders that the tested CC significantly $(\mathrm{p}<0.0001)$ improved QOL for symptoms, emotions, functioning and globally with greater improvements in emotions and functioning probably explained by the conditions treated. Moreover, the $\mathrm{CC}$ hydrated the skin and reduced skin tautness. Subject and investigator satisfaction after 4 weeks of use was very high and subjects highly appreciated the cosmetic quality of their CC. 


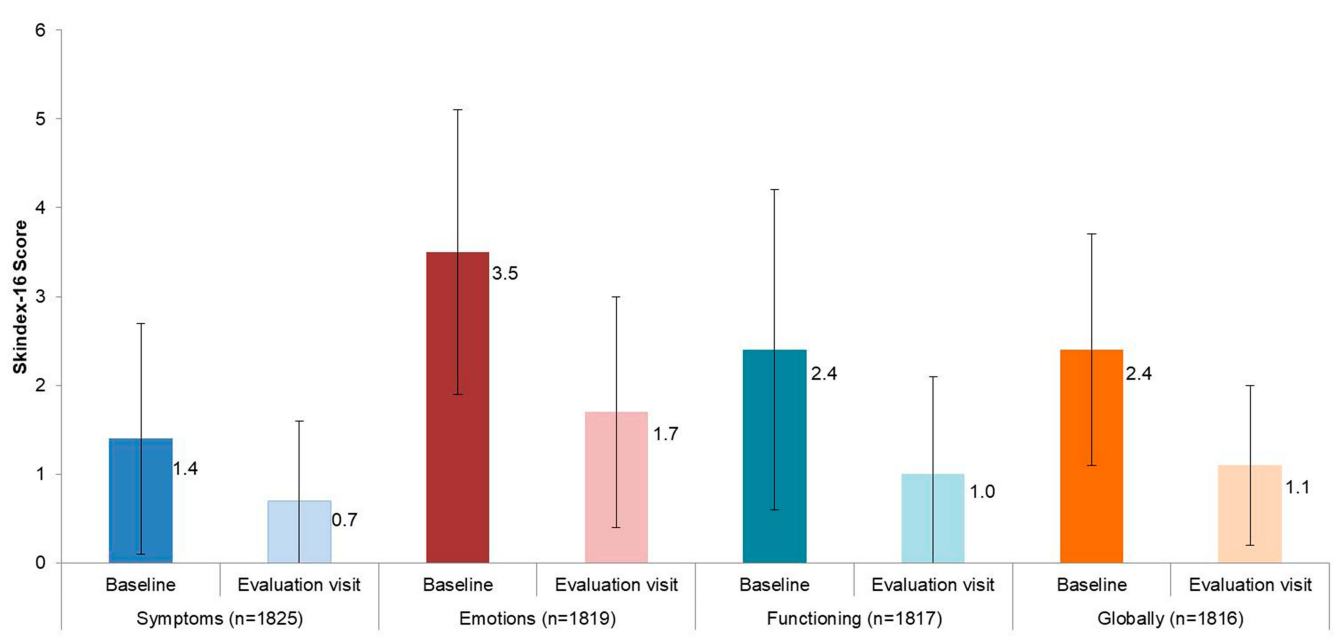

Figure I Skindex-16 score at baseline and after 4 weeks of daily application on the face.

Notes: Skindex-16 score: $0=$ not bothered at all, $10=$ always bothered. Changes from Baseline were all statistically significant $(p<0.000 \mathrm{I})$.

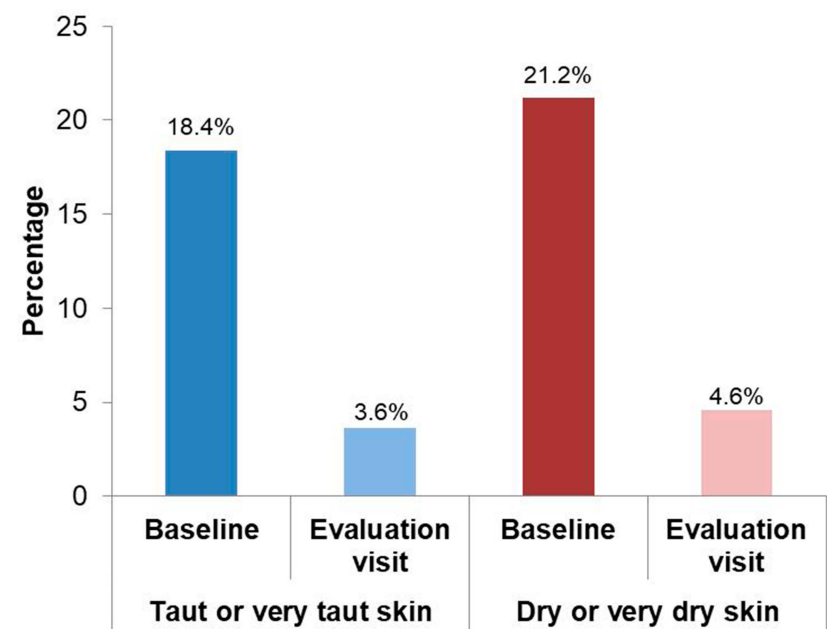

Figure 2 Prevalence of subjects with dry or very dry and with taut or very taut facial skin at baseline and after 4 weeks of daily application.

Note: A significant $(\mathrm{p}<0.000 \mathrm{I})$ decrease in the prevalence of subjects with dry and taut facial skin was observed after 4 weeks of use.

Specific corrective cosmetics and camouflage makeup are becoming more and more popular in the adjuvant care of facial blemishes resulting from primary (acne rosacea vitiligo, melasma) or secondary skin disorders (post-inflammatory hyperpigmentation, blemishes and disorders resulting from adverse reactions or side effects from therapies such as cancer or aesthetic surgery, scars) as they have been shown to improve skin aspect as well as QOL and self-esteem. ${ }^{16-22}$

However, certain products have only been developed to be specific to a particular type of facial blemish and to different skin phototypes. ${ }^{8,18,22}$ The tested highly corrective CC has been developed to suit all types of facial blemish and different skin phototypes. Moreover, it can be used in women, men and children, due to its excellent local tolerance. And it has shown to have a very high protection against visible light, now well recognized to induce or worsen pigmentation disorders. ${ }^{12}$

Despite these advantages, and even though camouflage make-up and corrective cosmetics are indicated for any gender and any age, our survey shows that a large majority of $\mathrm{CC}$ users are young women. ${ }^{23}$ This may be due to the fact that women care much more about physical aspects and may use makeup more easily than men. Regardless of this potential limitation, our data confirm the significant positive impact of the tested CC on the QOL of subjects with significant facial blemishes.

In conclusion, dermatologists should continue encouraging their patients regardless of gender or age with disfiguring dermatoses to use corrective cosmetics, thus improving skin appearance, well-being and their QOL.

\section{Acknowledgments}

The authors acknowledge the participation of the study investigators and of the participants and Karl Patrick Göritz, SMWS France, for writing support.

\section{Funding}

This study was funded by Laboratoires Vichy, France.

\section{Disclosure}

Delphine Kerob is an employee of Laboratoires Vichy, France. Catherine Delva is an employee of Sylia-Stat. The authors report no other conflicts of interest in this work. 


\section{References}

1. Sanclemente G, Burgos C, Nova J, et al. The impact of skin diseases on quality of life: a multicenter study. Actas Dermosifiliogr. 2017;108 (3):244-252. doi:10.1016/j.ad.2016.11.008

2. Kornhaber R, Visentin D, Thapa DK, et al. Cosmetic camouflage improves quality of life among patients with skin disfigurement: a systematic review. Body Image. 2018;27:98-108. doi:10.1016/j. bodyim.2018.08.004

3. Levy LL, Emer JJ. Emotional benefit of cosmetic camouflage in the treatment of facial skin conditions: personal experience and review. Clin Cosmet Investig Dermatol. 2012;5:173-182. doi:10.2147/CCID. S33860

4. Korichi R, Pelle-de-Queral D, Gazano G, Aubert A. Why women use makeup: implication of psychological traits in makeup functions. J Cosmet Sci. 2008;59(2):127-137.

5. Seite S, Deshayes P, Dreno B, et al. Interest of corrective makeup in the management of patients in dermatology. Clin Cosmet Investig Dermatol. 2012;5:123-128. doi:10.2147/CCID.S33172

6. Boehncke WH, Ochsendorf F, Paeslack I, Kaufmann R, Zollner TM. Decorative cosmetics improve the quality of life in patients with disfiguring skin diseases. Eur J Dermatol. 2002;12(6):577-580.

7. Draelos ZD. Colored facial cosmetics. Dermatol Clin. 2000;18 (4):621-631. doi:10.1016/S0733-8635(05)70213-8

8. Tanioka M, Yamamoto Y, Kato M, Miyachi Y. Camouflage for patients with vitiligo vulgaris improved their quality of life. $J$ Cosmet Dermatol. 2010;9(1):72-75. doi:10.1111/jcd.2010.9.issue-1

9. Ongenae K, Dierckxsens L, Brochez L, van Geel N, Naeyaert JM. Quality of life and stigmatization profile in a cohort of vitiligo patients and effect of the use of camouflage. Dermatology. 2005;210(4):279-285. doi:10.1159/000084751

10. Holme SA, Beattie PE, Fleming CJ. Cosmetic camouflage advice improves quality of life. $\mathrm{Br} J$ Dermatol. 2002;147(5):946-949. doi:10.1046/j.1365-2133.2002.04900.x

11. Merial-Kieny C, Nocera T, Mery S. [Medical corrective make-up in post- chemotherapy]. Ann Dermatol Venereol. 2008;(1):25-28. French.
12. Duteil L, Esdaile J, Maubert Y, et al. A method to assess the protective efficacy of sunscreens against visible light-induced pigmentation. Photodermatol Photoimmunol Photomed. 2017;33 (5):260-266. doi:10.1111/phpp.12325

13. Balkrishnan R, McMichael AJ, Hu JY, et al. Corrective cosmetics are effective for women with facial pigmentary disorders. Cutis. 2005;75 (3):181-187.

14. Chren MM, Lasek RJ, Sahay AP, Sands LP. Measurement properties of Skindex-16: a brief quality-of-life measure for patients with skin diseases. J Cutan Med Surg. 2001;5(2):105-110. doi:10.1007/BF02 737863

15. IEA. International epidemiological association: good epidemiological practice (GEP), IEA guidelines for proper conduct in epidemiological research. November 2007. Available from: http://ieaweb.org/goodepidemiological-practice-gep/. Accessed January 8, 2019.

16. Wakeda T, Okamura T, Kawahara T, Heike Y. Camouflage makeup improves quality of life in cancer patients with treatment-related skin changes. Tumori. 2019:300891619867844.

17. Filinte GT, Akoz T. Camouflage therapy in aesthetic surgery. Clin Dermatol. 2014;32(6):813-816. doi:10.1016/j.clindermatol.2014.02. 021

18. Hossain C, Porto DA, Hamzavi I, Lim HW. Camouflaging agents for vitiligo patients. J Drugs Dermatol. 2016;15(4):384-387.

19. Draelos ZD. Cosmeceuticals for rosacea. Clin Dermatol. 2017;35 (2):213-217. doi:10.1016/j.clindermatol.2016.10.017

20. McMichael L. Skin camouflage. BMJ. 2012;344:d7921. doi:10.1136/ bmj.d7921

21. Mee D, Wong BJ. Medical makeup for concealing facial scars. Facial Plast Surg. 2012;28(5):536-540. doi:10.1055/s-00000018

22. Monfrecola G, Cacciapuoti S, Capasso C, Delfino M, Fabbrocini G. Tolerability and camouflaging effect of corrective makeup for acne: results of a clinical study of a novel face compact cream. Clin Cosmet Investig Dermatol. 2016;9:307-313. doi:10.2147/CCID.S115192

23. Salsberg JM, Weinstein M, Shear N, Lee M, Pope E. Impact of cosmetic camouflage on the quality of life of children with skin disease and their families. J Cutan Med Surg. 2016;20(3):211-215. doi: $10.1177 / 1203475415595175$
Clinical, Cosmetic and Investigational Dermatology is an international, peer-reviewed, open access, online journal that focuses on the latest clinical and experimental research in all aspects of skin disease and cosmetic interventions. This journal is indexed on CAS.
The manuscript management system is completely online and includes a very quick and fair peer-review system, which is all easy to use. Visit http://www.dovepress.com/testimonials.php to read real quotes from published authors. 